\title{
Left Ventricular Systolic and Diastolic Function in the Hypertrophied Ventricle
}

\author{
Tetsu Yamakado, M.D. AND TAKeshi Nakano, M.D.
}

\begin{abstract}
To investigate left ventricular (LV) systolic and diastolic function in cardiac hypertrophy, we analysed LV pressure (catheter tip-manometer) and simultaneously performed cineangiography in 24 patients with systemic hypertension (HT), 25 patients with hypertrophic cardiomyopathy (HCM) and 25 normal subjects. We digitized LV cineangiograms frame by frame and computed volume and its derivatives, wall thickness and circumferential wall stress. LV systolic pump function was normal or supernormal in HT and HCM. However, myocardial contractility assessed by end-systolic wall stressvolume relation was depressed in HCM whereas it is normally maintained in HT. LV diastolic function was also impaired in HCM and even in HT despite normal systolic function. The LV hypertrophy group showed significantly prolonged time constant of isovolumic relaxation, increased time from endsystole to the peak filling rate, and upward shift of the diastolic pressurevolume relationship. The characteristic findings of LV diastolic function in LV hypertrophy, therefore, can be summarized as impaired isovolumic relaxation, delayed early diastolic filling and decreased diastolic distensibility. The mechanisms of abnormal systolic and diastolic function may include myocardial ischemia and/or calcium overload in hypertrophied myocardium, but further study will be needed to clarify these problems.
\end{abstract}

$\mathrm{C}^{2}$

ARDIAC hypertrophy is an important adaptive mechanism to maintain pump performance. It is also well known that hypertrophied hearts often develop heart failure. Despite many studies on the systolic and diastolic mechanics of the hypertrophied left ventricle, this phenomenon is not yet fully understood.

The purpose of this study was to investigate precisely left ventricular systolic and diastolic function in the hypertrophied ventricle of systemic hypertension and hypertrophic cardiomyopathy. This was done by direct measurement of left ventricular volume and pressure by biplane cineventriculography and catheter tip manometer. We analysed systolic global pump and myocardial function, and diastolic relaxation, filling and distensibility in the hypertrophied left ventricle.

Key words:

Left ventricular systolic function

Left ventricular diastolic function

Left ventricular hypertrophy

\section{SUBJECTS AND METHODS}

Study patients: We studied 24 patients with systemic hypertension, 25 patients with hypertrophic cardiomyopathy and 25 normal control subjects who had undergone cardiac catheterization. The normal and hypertensive groups underwent diagnostic catheterization because of atypical chest pain or electrocardiographic abnormalities but were found to have normal hemodynamics, normal left ventriculography and normal coronary arteries. Vasospastic angina was excluded in these subjects by performing an ergonovine or acetylcholine provocation test. The diagnosis of hypertrophic cardiomyopathy was based on clinical, echocardiographic, and angiographic evaluation. All subjects were in normal sinus rhythm and had received no drug treatment for at least 2 days before cardiac catheterization. No patient had a history of heart failure. No patient had a resting left ven-

The First Department of Internal Medicine, Mie University, Tsu, Japan

Mailing address: Tetsu Yamakado, M.D., The First Department of Internal Medicine, Mie University, Edobashi 2-174, Tsu 514, Japan 
TABLE I LEFT VENTRICULAR FUNCTION IN NORMAL SUBJECTS (N) (N=25), HYPERTENSION $(\mathrm{HT}) \quad(\mathrm{N}=24) \quad$ AND HYPERTROPHIC CARDIOMYOPATHY (HCM) $(\mathrm{N}=25)$

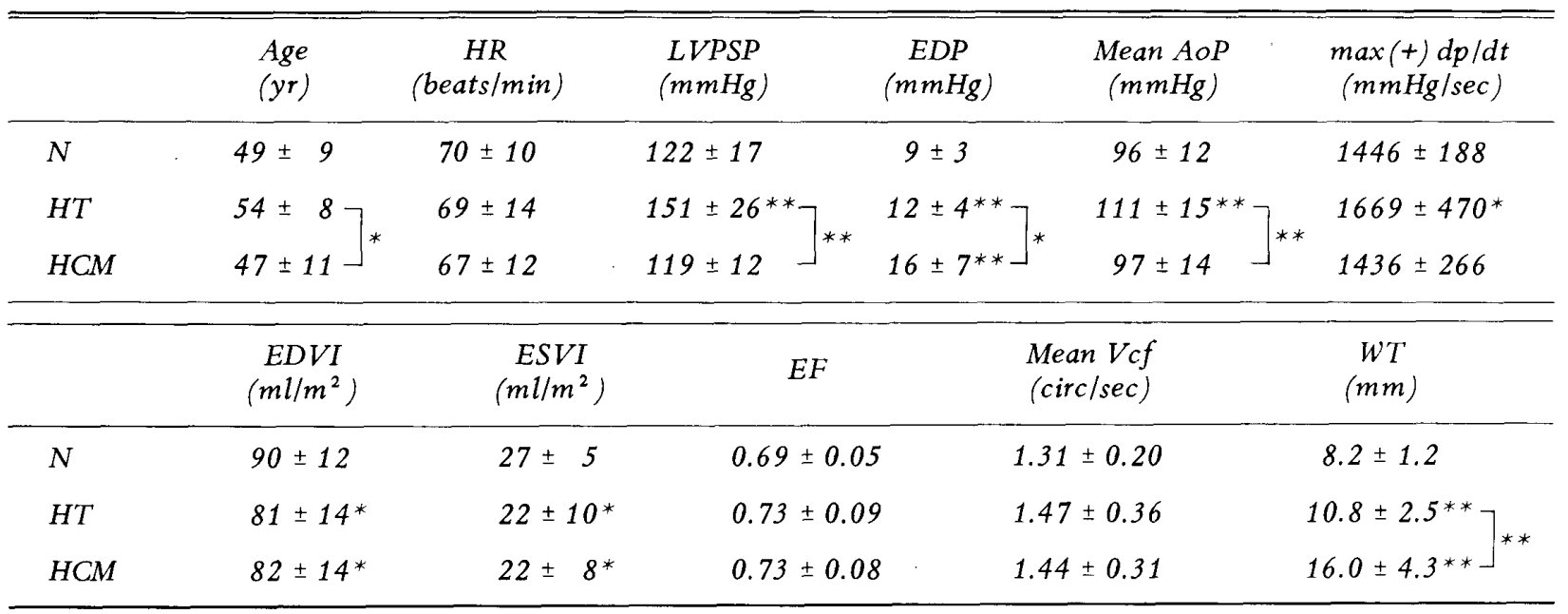

AoP = aortic pressure; $E D P=$ end-diastolic pressure; $E D V I=$ end-diastolic volume index; $E S V I=$ end-systolic volume index; $E F=$ ejection fraction; $H R=$ heart rate; $L V P S P=$ left ventricular peak systolic pressure; Vcf $=$ circumferential fiber shortening velocity; $W T=$ wall thickness; ${ }^{*}=p<0.005,{ }^{* *}=p<0.01$. All data were presented as mean $\pm S D$.

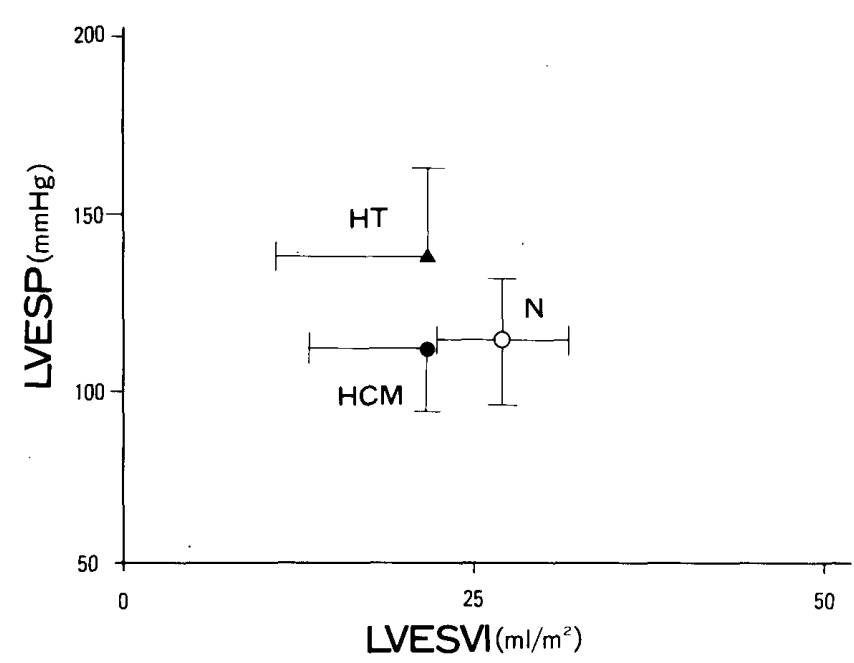

Fig.1. Left ventricular (LV) end-systolic pressure-volume index relation in normals (N), systemic hypertension (HT) and hypertrophic cardiomyopathy (HCM).

tricular outflow tract pressure gradient in hypertrophic cardiomyopathy.

Cardiac catheterization: Cardiac catheterization was performed via the percutaneous femoral approach in the fasting state and under premedication with hydroxyzine hydrochloride intramuscularly $(50 \mathrm{mg})$. Simultaneous biplane cineventriculograms were obtained in the $30^{\circ}$ right anterior oblique and $60^{\circ}$ left anterior oblique projections by injecting $40 \mathrm{ml}$ of contrast media at a rate of $12 \mathrm{ml} / \mathrm{sec}$. The film speed was 50 frames/sec. Central aortic and left ventricular pressures were measured with a pigtail angiographic micromanometer catheter (Millar Instruments, Inc.). Left ventricular pressures were recorded simultaneously during ventriculograms at a paper speed of $150 \mathrm{~mm} / \mathrm{sec}$ (Electronics for Medicine VR-12) along with the first derivative of pressure $(\mathrm{dP} / \mathrm{dt})$. An electrically triggered cine tracer marked the X-ray film and sent a timing signal to the recorder for simultaneous measurement of pressure and volume. The micromanometer-tipped catheter was calibrated against luminal pressures with a fluid-filled system. 

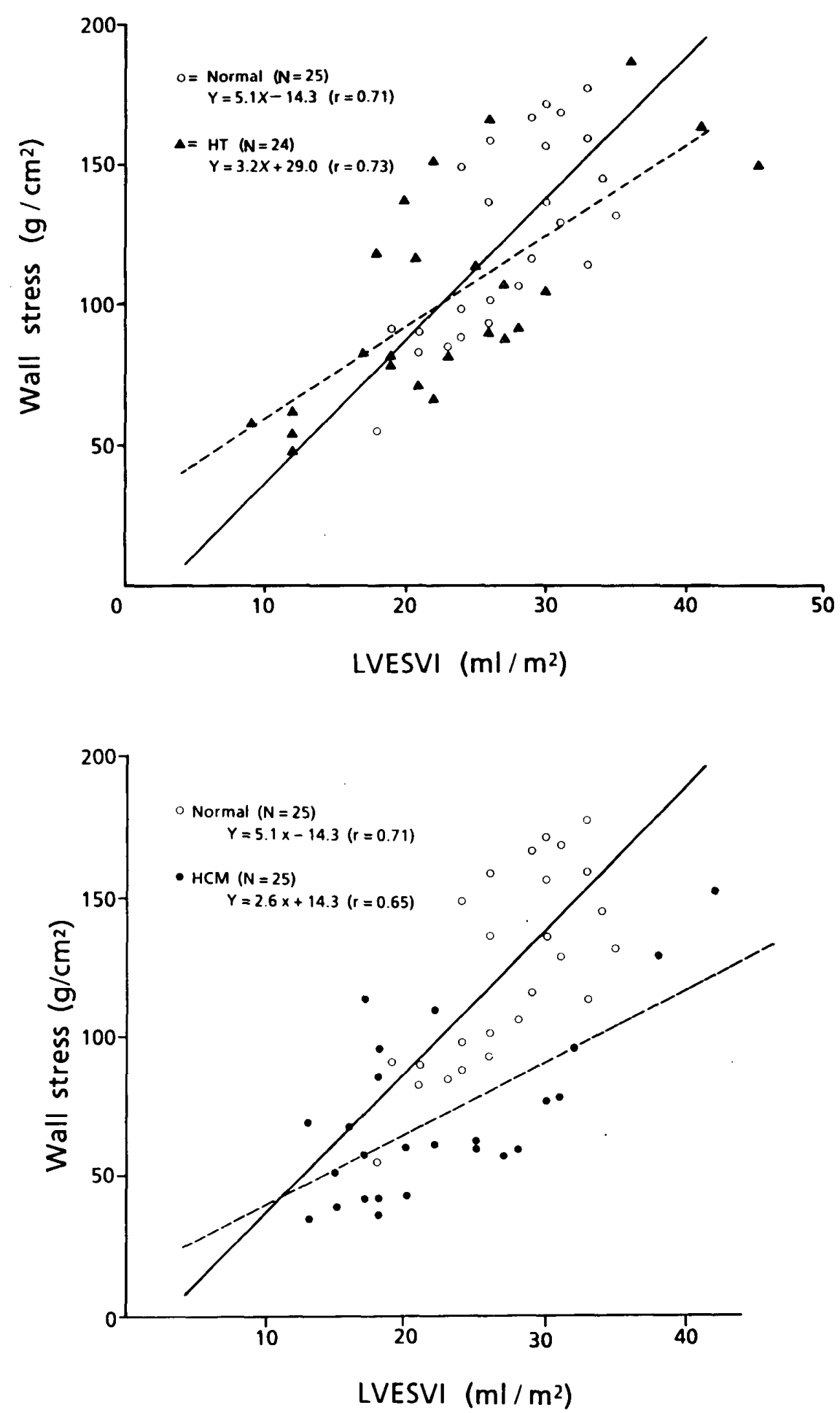

Fig.2. End-systolic circumferential wall stress-volume index relation in hypertension (HT) (upper) and hypertrophic cardiomyopathy (HCM) (lower) as compared with normal subjects $(\mathrm{N})$. LVESVI = left ventricular end-systolic volume index.

After left ventriculography, selective coronary angiography was performed in all patients.

Analysis of catheterization data: We analyzed biplane left ventricular silhouettes by digitizing frame by frame $(50 \mathrm{frame} / \mathrm{sec})$ and computed volumes and its derivatives, wall thickness, mass, and wall stress. All beats analyzed were with a sinus rhythm, and postextrasystolic beats were excluded. We computed left ventricular volume by the biplane area-length method! 

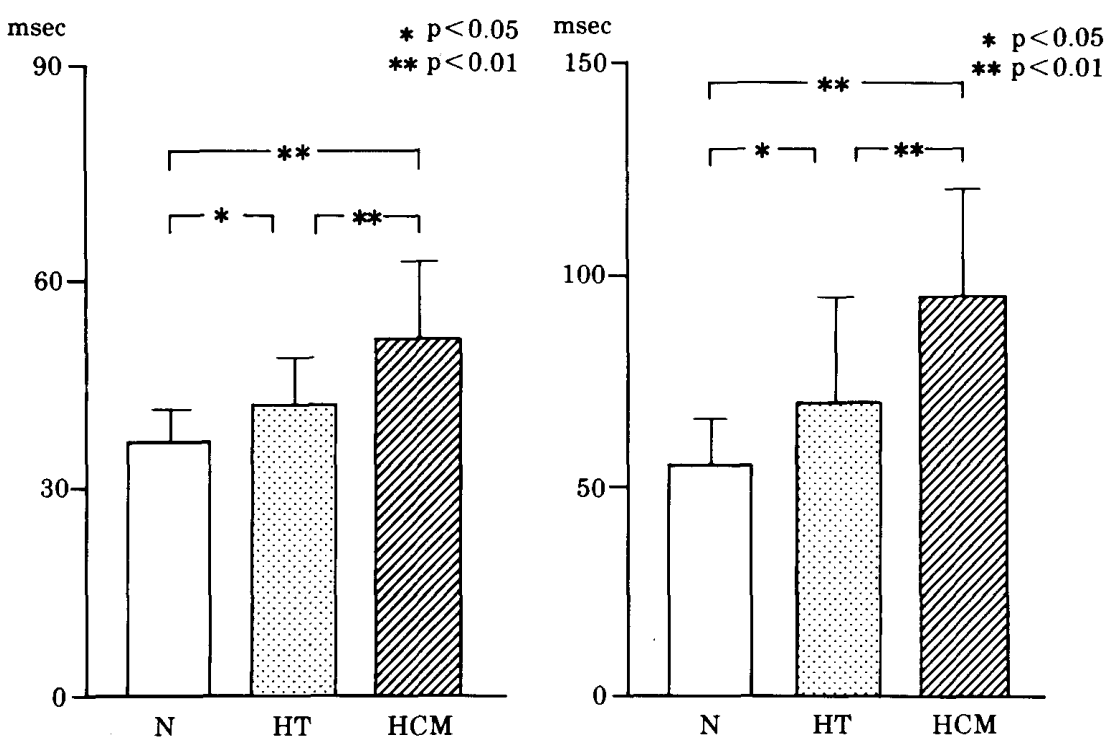

Fig.3. The time constant of left ventricular isovolumic pressure decay in normals $(\mathrm{N})$, hypertension (HT) and hypertrophic cardiomyopathy (HCM). The left panel shows the time constant calculated as asymptote zero, and the right panel shows the time constant with variable asymptotes.

Left ventricular wall thickness was measured by averaging the wall thickness of a $4 \mathrm{~cm}$ segment of the free left ventricular wall at approximately the junction of the apical and middle third? Left ventricular mass (LVM) was calculated as follows: $\operatorname{LVM}(\mathrm{g})=1.05\left[(\mathrm{pi} / 6)(\mathrm{a}+2 \mathrm{~h})(\mathrm{b}+2 \mathrm{~h})^{2}\right.$ - EDV], where a is the ventricular long axis, $b$ is the short axis as computed from the arealength relationship, and $h$ is wall thickness at end-diastole. Circumferential wall stress (WS) was calculated using Mirsky's equation ${ }^{3}$ : WS $\left(\mathrm{g} / \mathrm{cm}^{2}\right)=1.36 \quad(\mathrm{pb} / 2 \mathrm{~h}) \quad\left(1-\mathrm{b}^{2} / 2 \mathrm{a}^{2}-\mathrm{h} / \mathrm{b}+\mathrm{h}^{2} /\right.$ $\left.2 a^{2}\right)$.

To assess systolic pressure-volume and wall stress-volume relation.

We assessed left ventricular relaxation by the time constant of isovolumic pressure decay. To calculate the time constants of pressure decay, left ventricular pressure was measured every $5.0 \mathrm{msec}$ from the point of minimal $\mathrm{dP} / \mathrm{dt}$ to a level $5 \mathrm{mmHg}$ above the end-diastolic pressure of the next beat. Left ventricular pressure and time during this interval was fit by an exponential method with zero (Tw) or variable asymptotes $(\mathrm{Tb})$ to the following 2 equations: (1) $\mathrm{P}(\mathrm{t})=$ aebt, (2) $\mathrm{P}(\mathrm{t})=\mathrm{aebt}+\mathrm{c}$, where $\mathrm{P}$ is left ventricular pressure $(\mathrm{mmHg}), \mathrm{t}$ is time $(\mathrm{msec}), \mathrm{c}$ is the asymptote of pressure fall $(\mathrm{mmHg})$, and a and $\mathrm{b}$ are constants. From these equations, 2 time constants $(-1 / b)$ were calculated. To describe left ventricular early diastolic filling, we measured the peak diastolic filling rate (PFR) of volumes and the time from the end-systolic frame to the PFR (TPFR). The volume-time curve was smoothed using a polynomial approximation technique. The third-degree polynomial was fit to each set of 5 consecutive points using the method of least squares. After digitizing and filtering, the volumes were differentiated and the PFR and the TPFR were calculated. As the PFR seems to be affected by total left ventricular end-diastolic volume and stroke volume, the normalized PFR corrected for end-diastolic volume (PFR/EDV) and stroke volume (PFR/SV) was also calculated. To assess the alterations in left ventricular diastolic chamber compliance (distensibility), we plotted diastolic pressurevolume relations from the point of minimal left ventricular pressure to the top of the atrial pressure wave form.

Statistical analysis: Intergroup comparison of the hemodynamic variables was performed with an unpaired $t$ test. A significant difference was indicated by a $p$ value less than 0.05 . Values are expressed as the mean $\pm \mathrm{SD}$.

\section{RESULTS}

Left ventricular systolic function in the hypertrophied ventricle

Table I is a list of the left ventricular hemodynamic data in N, HT and HCM. There was no 
PFR

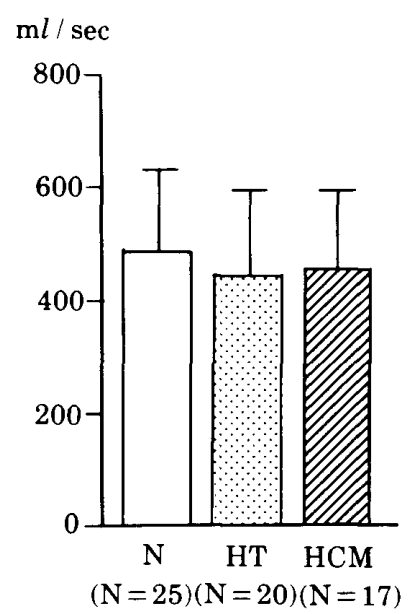

$\mathrm{PFR} / \mathrm{EDV}$

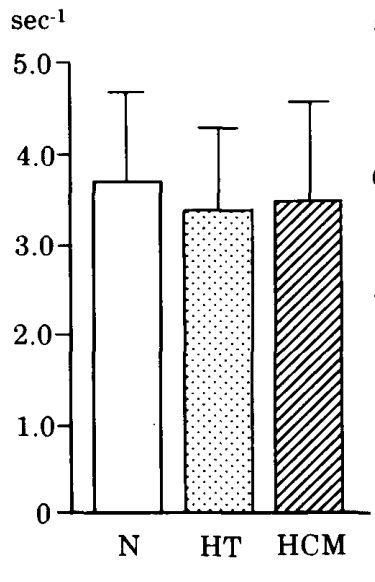

$\mathrm{PFR} / \mathrm{SV}$

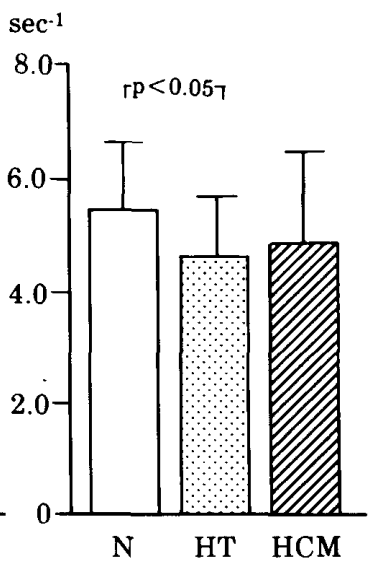

Fig.4. Diastolic peak filling rate (PFR) and normalized PFR of LV volume during rapid filling period in normals $(\mathrm{N})$, hypertension $(\mathrm{HT})$ and hypertrophic cardiomyopathy $(\mathrm{HCM}) . \mathrm{EDV}=$ end-diastolic volume, $\mathrm{SV}=$ stroke volume.

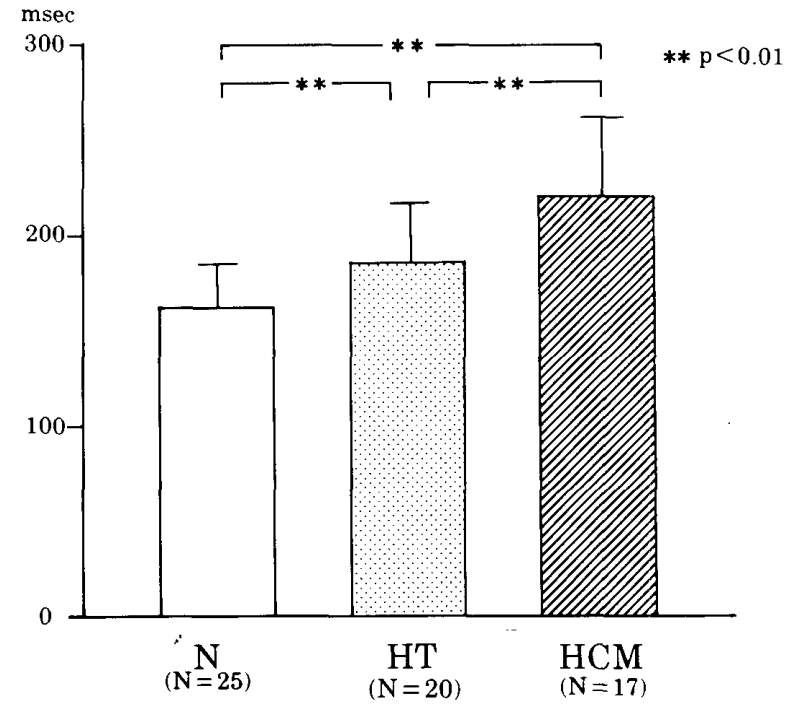

Fig.5. The time from end-systole to the peak filling rate in normals $(\mathrm{N})$, hypertension (HT) and hypertrophic cardiomyopathy (HCM).

significant difference in heart rate in the 3 groups. LV peak systolic pressure and mean aortic pressure were significantly higher in HT compared with $\mathrm{N}$ and HCM. The mean values of LV end-diastolic pressure and wall thickness were significantly greater in the LV hypertrophy group of HT and HCM than that in N, and both values were greater in HCM than HT. There was a significant decrease in both $\mathrm{LV}$ end-diastolic and end-systolic volume in HT and HCM compared with $\mathrm{N}$. Ejection fraction and mean $\mathrm{Vcf}$ was greater in HT and HCM, but it did not reach statistical significance. The end-systolic pressurevolume relationship of the 3 groups is shown in Fig. 1. It shifted leftward (HCM) or leftward and upward (HT) compared with $\mathrm{N}$, indicating increased LV chamber contractility in the $2 \mathrm{LV}$ hypertrophy groups.

Figure 2 shows the end-systolic wall stressvolume relationship in the 3 groups. A good first order correlation between end-systolic wall stress and end-systolic volume index was observed in all 3 groups (range of correlation coefficient; $0.65-0.73$ ). The relations of $\mathrm{N}$ and $\mathrm{HT}$ were in general very close to each other (upper panel). In contrast, the relationship in HCM tended to shift downward and the mean slope of the relation was significantly lower than $\mathrm{N}$ (lower panel). These findings suggest that myocardial contractility evaluated by force-length relation may be depressed in HCM, whereas it is normally maintained in HT.

\section{$L V$ diastolic function in the hypertrophied ventricle}

The time constants of $\mathrm{LV}$ isovolumic pressure decay were significantly prolonged in $\mathrm{HT}$ and HCM as compared with $\mathrm{N}$ (Tw: $\mathrm{N} ; 37 \pm 4 \mathrm{msec}$, $\mathrm{HT} ; 42 \pm 7 \mathrm{msec}, \mathrm{HCM} ; 52 \pm 11 \mathrm{msec}, \mathrm{Tb}: \mathrm{N}$; $55 \pm 11 \mathrm{msec}, \mathrm{HT} ; 70 \pm 25 \mathrm{msec}, \mathrm{HCM} ; 95 \pm 25$ $\mathrm{msec}$ ), suggesting impaired isovolumic relaxation in the LV hypertrophy group. The time constants were significantly greater in HCM than HT (Fig. 3).

During the rapid filling period the PFR of LV 


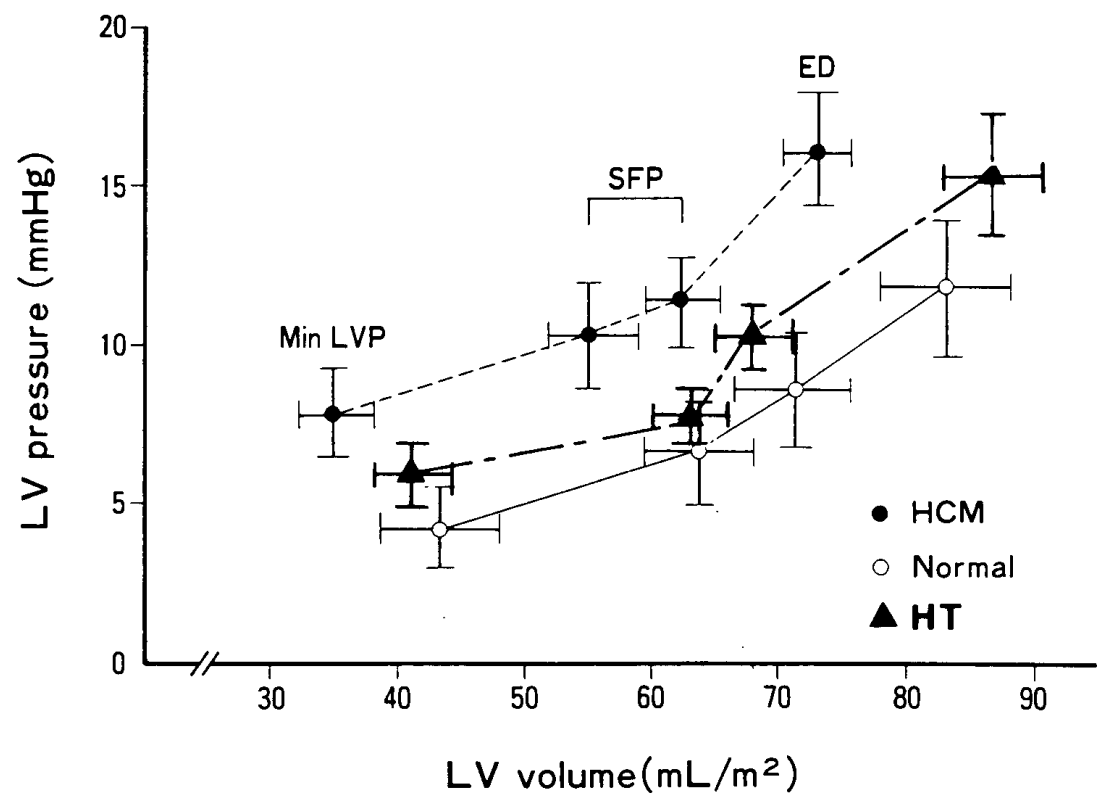

Fig.6. Left ventricular diastolic pressure-volume index relationship in normals (N), hypertension (HT) and hypertrophic cardiomyopathy (HCM). Min LVP = minimal left ventricular pressure, $\mathrm{SF}=$ slow filling period, $\mathrm{ED}=$ end-diastole.

volume and normalized PFR (PFR/EDV and $\mathrm{PFR} / \mathrm{SV}$ ) were not significantly different in the 3 groups, except for a significant difference of PFR/SV between N and HT (Fig. 4). However, the time from end-systole to PFR (TPFR) was significantly greater in the LV hypertrophy group of HT $(186 \pm 31 \mathrm{msec})$ and HCM $(220 \pm 42 \mathrm{msec})$ than that in $\mathrm{N}(162 \pm 23 \mathrm{msec})$ and it was more prolonged in HCM than HT (Fig. 5). The TPFR was positively related to the degree of LV mass (correlation coefficient; 0.42).

The diastolic pressure-volume relation shifted upward in the LV hypertrophy group, particularly in $\mathrm{HCM}$ in comparison with $\mathrm{N}$, indicating decreased LV diastolic distensibility (Fig. 6).

\section{DISCUSSION}

In this study, LV systolic pump function was almost normal and LV chamber contractility seemed to be supernormal as assessed by the endsystolic pressure-volume relaltion in patients with HT and HCM. LV myocardial contractility as assessed by end-systolic wall stress-volume relation was normal in HT, but was depressed in HCM. On the other hand, LV diastolic function was abnormal in both HT and HCM, characterized by impaired isovolumic relaxation, delayed early diastolic filling and decreased distensibility.

Early studies demonstrated that many patients with HT have normal ventricular performance as assessed by ejection phase indices, whereas some patients with severe hypertrophy or cardiac dilatation have depressed ventricular performance? ${ }^{7-10}$ However, it is controversial whether the depressed systolic pump function in HT is due to afterload mismatch or decreased myocardial contractility as assessed by force-velocitylength framework ${ }^{8-10}$ It is reported that in patients with moderate hypertrophy the myocardial contractile state appears to be maintained, but it may be depressed in patients with severe hypertrophy.1 Our patients had mild and moderate LV hypertrophy without dilatation. It thus appears that mild or moderate LV hypertrophy caused by pressure overload was associated with almost normal LV pump function and myocardial contractility.

As for HCM, Hirota et al ${ }^{12}$ and Pouleur et al, ${ }^{13}$ using LV cineangiography and a catheter tip manometer, reported that myocardial contractility assessed by end-systolic wall stress-volume, mean Vcf and EF relation was normal or depressed as compared with $\mathrm{N}$ in this disorder whereas LV pump function was normal or supernormal. Our study supports their findings. This finding may be of clinical importance because recent studies have demonstrated that some patients with HCM develop overt congestive heart failure with cardiac dilatation $!^{14}$ Although the exact mechanism of myocardial contractile dysfunction in HCM is unclear, it is postulated 
that myocardial ischemia associated with small coronary artery disease ${ }^{15}$ and that decreased coronary flow reserve ${ }^{16}$ may possibly be one of the causative mechanisms. To test this hypothesis and investigate other factors, further studies will be needed.

Recent studies have demonstrated that patients with LV hypertrophy usually have abnormal diastolic function. We also observed that LV diastolic function was impaired in HCM and even hypertensive patients with normal pump function and myocardial contractility. The LV isovolumic relaxation has been invasively assessed by the time constant of isovolumic pressure decay. However, there are some methological problems in its calculation. ${ }^{17}$ Not only the patients with HCM but also those with HT associated with mild and moderate LV hypertrophy had significant prolongation of both the time constants in this study, implying that the slowing of isovolumic relaxation seems to be a sensitive marker of LV hypertrophy. Several studies have suggested that early diastolic filling is also impaired in cardiac hypertrophy, in addition to impairment of isovolumic relaxation. ${ }^{18-21}$ However, we did not observe abnormal early diastolic filling assessed by PFR and normalized PFR in HT and HCM except a significant difference of $\mathrm{PFR} / \mathrm{SV}$ between $\mathrm{N}$ and HT. The rate of LV early diastolic filling seems mainly to be determined by relaxation rate, the magnitude of left atrio (LA)-LV pressure gradients, the elastic recoil and probably LV diastolic compliance. ${ }^{22,23}$ In this study, a significant decrease in $L V$ end-systolic volume index might enhance the elastic recoil in HT and HCM, resulting in increased early diastolic filling rate. Although we did not make direct measurements of LA-LV pressure gradients, it can be postulated that a compensatory increase in LA driving pressure might also maintain rate normally. On the other hand, the TPFR was significantly prolonged in LV hypertrophy and was roughly but significantly correlated with LV mass. So, the TPFR, rather than the PFR or normalized PFR, seems to be a relatively sensitive index of early diastolic filling in LV hypertrophy.

The LV diastolic pressure-volume relation tended to shift upward (decreased diastolic distensibility) in the LV hypertrophy group, particularly in HCM. LV hypertrophy itself shifts the diastolic pressure-volume relation? The other major factors affecting the relation are the isovolumic relaxation rate, extrinsic constraint (pericardial constraint and ventricular interaction) and diastolic chamber stiffness. ${ }^{24}$ Impaired isovolumic relaxation (incomplete relaxation) might be associated with an upward shift particularly during early diastole. Pericardial effect may be negligible in the steady. state condition. The right atrial or right ventricular pressures were not simultaneously obtained with LV pressure, but ventricular interaction does not seem to play a significant role in cardiac hypertrophy. ${ }^{25}$ At present, there is no accurate and established method to evaluate LV diastolic chamber stiffness. Based on the above considerations, the mechanisms of upward shift of the diastolic pressure-volume relation may be complex and it seems to be, at least, related to $\mathrm{LV}$ hypertrophy and incomplete relaxation.

Finally, what is responsible for LV diastolic dysfunction in LV hypertrophy? Recent studies have suggested that some patients with abnormal diastolic filling in HT may improve after regression of LV hypertrophy by anti-hypertensive agents. ${ }^{26,27}$ Several investigators have suggested that calcium blocking agents improve abnormal LV diastolic function in HCM and that impaired diastolic function may be associated with calcium overload in hypertrophied myocardium. ${ }^{28-31}$ However, in a previous study we showed that sublingual nifedipine did not improve LV diastolic dysfunction in patients with asymptomatic or minimally symptomatic $\mathrm{HCM}^{32}$ It is therefore speculated that cardiac hypertrophy itself may be responsible for abnormal diastolic function in mild form or early-stage hypertrophy, and that calcium overload, myocardial ischemia and other unknown factors may further aggravate diastolic function in severe or end-stage hypertrophy.

\section{REFERENCES}

1. WYNNE J, GREEN LH, MANN T, LEVIN D, GROSSMAN W: Estimation of left ventricular volumes in man from biplane cineangiograms filmed in oblique projections. Am J Cardiol 41: 726,1978

2. RACKLEY CE, DODGE HT, COLE WD, HAY RE: A method for determining left ventricular mass in man. Circulation 29: 666, 1964

3. MIRSKY I: Elastic properties of the myocardium: a quantitative approach with physiological and clinical applications. In Handbook of Physiology. Section 2. The Cardiovascular System. Volume 1. The Heart, ed by BERNE RM, American Physiological Society, Bethesda, Maryland, 1979, p 497

4. WEISS JL, FREDERIKSEN JW, WEISSFELDT ML: Hemodynamic determinants of the time- 
course of fall in canine ventricular pressure. $J$ Clin Invest 58: 751, 1976

5. THOMPSON DS, WALDRON CB, COLTART DJ, JENKINS BS, WEBB-PEPLOE MM: Estimation of time constant of left ventricular relaxation. $\mathrm{Br}$ Heart J 49: 250, 1983

6. HAMMERMEISTER KE, WARBASSE JR: The rate of change of left ventricular volume in man. II. Diastolic events in health and disease. Circulation 49: 739, 1974

7. KARLINER JS, WILLIAM D, GORWIT W, CRAWFORD MH, O'ROURKE RA: Left ventricular performance in patients with left ventricular hypertrophy caused by systemic hypertension. Br Heart J 39: 1239, 1977

8. STRAUER B: Ventricular function and coronary hemodynamics in hypertensive heart disease. $A m$ J Cardiol 44: 999, 1979

9. GUAZZI $M$, FIORENTINI $C$, OLIVARI MT, POLESE A: Cardiac load and function in hypertension. Am J Cardiol 44: 1007, 1979

10. NICHOLS AB, SCIACCA RR, WEISS MB, BLOOD DK, BRENNAN DL, CANNON PJ: Effect of left ventricular hypertrophy on myocardial blood flow and ventricular performance in systemic hypertension. Circulation 62: 329, 1980

11. TAKAHASHI M, SASAYAMA $S$, KAWAI C, KOTOURA $\mathrm{H}$ : Contractile performance of the hypertrophied ventricle in patients with systemic hypertension. Circulation 62: 16, 1980

12. HIROTA $\mathrm{Y}$, FURUBAYASHI $\mathrm{K}$, KAKU $\mathrm{K}$, SHIMIZU G, KINO M, KAWAMURA $\mathrm{K}$, TAKATSU T: Hypertrophic nonobstructive cardiomyopathy: a precise assessment of hemodynamic characteristics and clinical implications. Am J Cardiol 50: 990, 1982

13. POULEUR H, ROUSSEAU MF, VAN EYLL C, BRASSEUR LA, CHARLIER AA: Force-velocitylength relations in hypertrophic cardiomyopathy: evidence of normal or depressed myocardial contractility. Am J Cardiol 52: 813, 1983

14. FUJIWARA $\mathrm{H}$, ONODERA T, TANAKA M, SHIRANE $\mathrm{H}$, KATO $\mathrm{H}$, YOSHIKAWA J, OSAKADA G, SASAYAMA S, KAWAI C: Progression from hypertrophic obstructive cardiomyopathy to typical dilated cardiomyopathy-like features in the end-stage. Jpn Circ J 48: 1210, 1984

15. TANAKA M, FUJIWARA H, ONODERA T, WU DJ, MATSUDA M, HAMASHIMA Y, KAWAI C: Quantitative analysis of narrowing of intramyocardial small arteries in normal hearts, hypertensive hearts, and hearts with hypertrophic cardiomyopathy. Circulation 75: 1130, 1987

16. CANNON RO, ROSING DR, MARON BJ, LEON MB, BONOW RO, WATSON RM, EPSTEIN SE: Myocardial ischemia in patients with hypertrophic cardiomyopathy: contribution of inadequate vasodilator reserve and elevated left ventricular filling pressures. Circulation 71: 234, 1985

17. MIRSKY I: Assessment of diastolic function: suggested methods and future considerations. Circulation 69: 836, 1984

18. SANDERSON JE, GIBSON DG, BROWN DJ, GOODWIN JF: Left ventricular filling in hypertrophic cardiomyopathy: an angiographic study.
Br Heart J 39: 661, 1977

19. ST. JOHN SUTTON MG, TAJIK AJ, GIBSON DG, BROWN DJ, SEWARD JB, GIULIANI ER: Echocardiographic assessment of left ventricular filling and septal and posterior wall dynamics in idiopathic hypertrophic subaortic stenosis. Circulation 57: 512,1978

20. HANRATH P, MATHEY DG, SIEGERT R, BLEIFELD W: Left ventricular relaxation and filling pattern in different forms of left ventricular hypertrophy: an echocardiographic study. $A m J$ Cardiol 45: 15, 1980

21. SMITH VE, SCHULMAN P, KARIMEDDINI MK, WHITE WB, MEERAN MK, KATZ AM: Rapid ventricular filling in left ventricular hypertrophy: pathologic hypertrophy. $J A m$ Coll Cardiol 5: 869,1985

22. CARROLL JD, HESS OM, HIRZEL HO, KRAYENBUEHL HP: Dynamics of left ventricular filling at rest and during exercise. Circulation 68: 59, 1983

23. ISHIDA Y, MEISNER JS, TSUJIOKA K, GALLO JS, YORAN C, FRATER RWM, YELLIN EL: Left ventricular filling dynamics: influence of left ventricular relaxation and left atrial pressure. Circulation 74: 187, 1986

24. CARROLL JD, LANG RM, NEUMANN AL, BOROW KM, RAJFER SI: The differential effects of positive inotropic and vasodilator therapy on diastolic properties in patients with congestive cardiomy opathy. Circulation 74: 815, 1986

25. SLINKER BK, CHAGAS ACP, GLANTZ SA: Chronic pressure overload hypertrophy decreases direct ventricular interaction. Am J Physiol 253: H347, 1987

26. INOUYE IK, MASSIE BM, LOGE X, SIMPSON P, TUBAU JF: Failure of antihypertensive therapy with diuretic, beta blocking and calcium-blocking drugs to consistently reverse left ventricular diastolic filling abnormalities. Am $J$ Cardiol 53: 1583,1984

27. SMITH VE, WHITE WB, MEERAN MK, KARIMEDDINI MK: Improved left ventricular filling accompanies reduced left ventricular mass during therapy of essential hypertension. $J \mathrm{Am}$ Coll Cardiol 8: 1449, 1986

28. HANRATH $P$, MATHEY DG, KREMER $P$, SONNTAG F, BLEIFELD W: Effect of verapamil on left ventricular isovolumic relaxation time and regional left ventricular filling in hypertrophic cardiomyopathy. Am J Cardiol 45: 1258,1980

29. BONOW RO, OSTROW HG, ROSING DR, CANNON RO, LIPSON LC, MARON BJ, KENT KM, BACHRACH SL, GREEN MV: Verapamil effects on left ventricular systolic and diastolic function in patients with hypertrophic cardiomyopathy: pressure-volume analysis with a nonimaging scintillation probe. Circulation 68: 1062 , 1983

30. LORELL BH, PAULUS WJ, GROSSMAN W, WYNNE J, COHN PF: Modification of abnormal left ventricular diastolic properties by nifedipine in patients with hypertrophic cardiomyopathy. Circulation 65: 499, 1982

31. PAULUS WJ, LORELL BH, CRAIG WE, WYNNE J, MURGO JP, GROSSMAN W: Comparison of 
the effects of nitroprusside and nifedipine on diastolic properties in patients with hypertrophic cardiomyopathy: altered left ventricular loading or improved muscle inactivation? $\mathrm{J} \mathrm{Am}$ Coll Cardiol 2: 879, 1983
32. YAMAKADO $T$, OKANO $S$, HIGASHIYAMA $S$, NAKANO $T$, TAKEZAWA $H$ : Does nifedipine improve left ventricular diastolic function in hypertrophic cardiomyopathy? Circulation 74: II-228, 1986 